\title{
Crosstalk between epithelial- mesenchymal transition and castration resistance mediated by Twist1/AR signaling in prostate cancer
}

\author{
Masaki Shiota', Momoe Itsumi', Ario Takeuchi', Kenjiro Imada', \\ Hidetoshi Kuruma ${ }^{3}$, Junichi Inokuchi', Katsunori Tatsugami', Takeshi Uchiumi ${ }^{4}$, \\ Yoshinao Oda ${ }^{2}$ and Seiji Naito' \\ Departments of ${ }^{1}$ Urology, and ${ }^{2}$ Anatomic Pathology, Graduate School of Medical Sciences, Kyushu University, \\ 3-1-1 Maidashi, Higashi-ku, Fukuoka 812-8582, Japan \\ ${ }^{3}$ Department of Urology, School of Medicine, Jikei University, Tokyo 105-0003, Japan \\ ${ }^{4}$ Department of Clinical Chemistry and Laboratory Medicine, Graduate School of Medical Sciences, \\ Kyushu University, 3-1-1 Maidashi, Higashi-ku, Fukuoka 812-8582, Japan
}

\author{
Correspondence \\ should be addressed \\ to A Yokomizo \\ Email \\ yokoa@uro.med. \\ kyushu-u.ac.jp
}

\begin{abstract}
Although invasive and metastatic progression via the epithelial-mesenchymal transition (EMT) and acquisition of resistance to castration are both critical steps in prostate cancer, the molecular mechanism of this interaction remains unclear. In this study, we aimed to elucidate the interaction of signaling between castration resistance and EMT, and to apply this information to the development of a novel therapeutic concept using transforming growth factor- $\beta$ (TGF- $\beta$ ) inhibitor SB525334 combined with androgen-deprivation therapy against prostate cancer using an in vivo model. This study revealed that an EMT inducer (TGF- $\beta$ ) induced full-length androgen receptor (AR) and AR variant expression. In addition, a highly invasive clone showed augmented full-length $A R$ and $A R$ variant expression as well as acquisition of castration resistance. Conversely, full-length $A R$ and $A R$ as well as Twist 1 and mesenchymal molecules variant expression were up-regulated in castration-resistant $\mathrm{LNCaP}$ xenograft. Finally, TGF- $\beta$ inhibitor suppressed Twist 1 and AR expression as well as prostate cancer growth combined with castration. Taken together, these results demonstrate that Twist1/AR signaling was augmented in castration resistant as well as mesenchymal-phenotype prostate cancer, indicating the molecular mechanism of mutual and functional crosstalk between EMT and castration resistance, which may play a crucial role in prostate carcinogenesis and progression.
\end{abstract}

\footnotetext{
Key Words

- androgen-deprivation therapy

- androgen receptor

- castration resistance

- epithelial-mesenchymal transition

- prostate cancer

- Twist1
}

\section{Introduction}

Prostate cancer is the most common non-cutaneous cancer and the second leading cause of cancer-related mortality among the male population in Western countries. Most prostate cancers are initially dependent on androgens for tumor growth and respond well to androgen-deprivation therapy (ADT), which is the gold

Published by Bioscientifica Ltd
Endocrine-Related Cancer (2015) 22, 889-900 
standard for recurrent or advanced prostate cancer (Sharifi et al. 2010). However, most of these tumors will eventually relapse in a castration-resistant fashion during $\mathrm{ADT}$, which is defined as castration-resistant prostate cancer (CRPC) (Scher et al. 2008). A critical step in the development to CRPC involves the aberrant activation of androgen receptor (AR) signaling, despite low levels of serum androgen (Chen et al. 2008). The mechanism for aberrant AR signaling is attributable to AR overexpression, $A R$ mutations, AR co-regulators, AR activation by intracellular signal-transduction pathways, de novo androgen synthesis, and AR splice-variants (Chen et al. 2008). After becoming castration resistant, effective therapeutic options are limited, and the end result is often fatal. Accordingly, the development of a novel strategy for preventing the progression to castration resistance and for treating CRPC is urgently required (Shiota et al. 2013a).

Acquisition of migratory properties is a prerequisite for cancer to invade into cancer-surrounding tissue. Cancer invasion requires dramatic morphological and functional alterations, termed epithelial-mesenchymal transition (EMT), whereby cancer cells lose epithelial characteristics, but acquire a mesenchymal phenotype (Thiery \& Sleeman 2006). E-cadherin is an adhesion molecule and an epithelial marker, the loss of which leads to increased cellular invasion and motility (Schmalhofer et al. 2009). Conversely, N-cadherin, fibronectin, and vimentin are mesenchymal markers that provide mesenchymal abilities (Zeisberg \& Neilson 2009). The loss of epithelial cell markers such as E-cadherin with concomitant gain of mesenchymal markers, including N-cadherin, fibronectin, and vimentin, are hallmarks of EMT. The expression of EMT-related molecular markers is regulated by several E-box (5'-CANNTG-3')-binding transcription factors (Shiota et al. 2012a).

The basic helix-loop-helix transcription factor Twist1 is known to regulate the expression of target genes and to promote EMT (Ansieau et al. 2010). We have previously shown that Twist1 promoted prostate cancer growth through the regulation of AR expression (Shiota et al. 2010, 2014). In addition, Twist 1 was up-regulated following androgen ablation in human prostate cancer tissues (Shiota et al. 2012b), suggesting that Twist1 confers castration resistance to androgen-dependent prostate cancer. Thus, a molecular relationship between EMT and castration resistance induced by the common transcription factor Twist1 is implied.

Clinical findings have also shown that highly metastatic prostate cancer is more likely to become castration resistant (Cooperberg et al. 2009). Furthermore, circulating-tumor cell (CTC) counts may predict therapeutic effect and increase along with the development of castration resistance after suppression by ADT, suggesting that CRPC may easily form in metastatic regions via CTC dissemination (Danila et al. 2011, Miyamoto et al. 2012). However, to date, the biological and molecular basis of the relationship between EMT and castration resistance remains obscure. Therefore, in this study, we aim to define the mechanism by which Twist 1 mediates the mutual regulation between EMT and castration resistance through regulation of AR signaling.

\section{Materials and methods}

\section{Cell culture}

Human prostate cancer LNCaP and 22Rv1 cells were obtained from American Type Culture Collection (Manassas, VA, USA) and authenticated by STRS analysis. C4-2 cells which were established from LNCaP cells and commonly utilized cell lines authenticated by wholegenome and whole-transcriptome sequencing on an Illumina Genome Analyzer IIx platform (Lamoureux et al. 2011) were kindly provided by Dr Martin Gleave (Vancouver Prostate Centre, Vancouver, BC, Canada). Cells were cultured in Roswell Park Memorial Institute (RPMI) 1640 media, which was purchased from Life Technologies Corporation supplemented with $10 \%$ fetal bovine serum (FBS). All cell lines were passaged $<35$ times before use. 22Rv1/transforming growth factor (TGF) cells were established by long-term culture in the appropriate medium containing $5 \mathrm{ng} / \mathrm{ml}$ of human TGF- $\beta 1$ recombinant protein (RD Systems, Minneapolis, MN, USA). Highly invasive clones of $22 \mathrm{Rv} 1$ cells $(22 \mathrm{Rv} 1 / \mathrm{HI})$ were established by four selection iterations of invaded cells through an 8 - $\mu \mathrm{m}$ pore matrigel chamber (BD Biosciences, San Jose, CA, USA) and maintained in RPMI1640 media. The cell lines were maintained in a $5 \% \mathrm{CO}_{2}$ atmosphere at $37{ }^{\circ} \mathrm{C}$. When using TGF- $\beta 1$ and dihydrotestosterone (DHT), media were changed to serum free or $10 \%$ charcoal-stripped serum (CSS) supplemented respectively.

\section{Antibodies and reagents}

Antibodies against AR (N-20, sc-816) which recognizes $\mathrm{N}$-terminus of AR protein and Twist1 (sc-81417) were purchased from Santa Cruz Biotechnology. Anti-phosphorylated Smad2/3 (p-Smad2/3; \#8828) and anti-Smad2/3 (\#8685) antibodies were obtained from Cell

Published by Bioscientifica Ltd 
Signaling Technology (Cambridge, MA, USA). Antibodies against E-cadherin (\#610181), N-cadherin (\#610920), fibronectin (\#610077), and vimentin (\#550513) were purchased from BD Biosciences. Anti- $\beta$-actin (A3854) and anti-AR V7 (AG10008) antibodies were obtained from Sigma-Aldrich and Precision Antibody (Columbia, MD, USA) respectively. Anti-AR V7 (AG10008) antibody from Precision Antibody was utilized only for blotting AR V7 while anti-AR antibody (N-20) from Santa Cruz Biotechnology was utilized for blotting full-length AR and AR splice variants (AR-Vs) in all other experiments. TGF- $\beta$ inhibitor SB525334 was obtained from Sigma-Aldrich.

\section{Knockdown analysis using siRNAs}

The following double-stranded RNA 25-bp oligonucleotides were commercially generated (Life Technologies Corporation): 5'-CUUCCUCGCUGUUGCUCAGGCUGUC-3' (sense) and 5'-GACAGCCUGAGCAACAGCGAGGAAG-3' (antisense) for Twist1. Prostate cancer cells were transfected with siRNA using Lipofectamine 2000 (Life Technologies Corporation) according to the manufacturer's protocol.

\section{RNA isolation, RT, and quantitative real-time PCR}

RNA isolation and RT were performed as described previously (Shiota et al. 2010, 2011a, 2012b). Quantitative real-time PCR was performed using TaqMan Gene Expression Assays for Twist1 (Hs00361186_m1), fulllength $A R$ (Hs00907244_m1), AR V7 (custom-made; primer and probe sequences were described previously in Liu et al. (2014)), fibronectin (Hs01549976_m1), vimentin (Hs00185584_m1), and glyceraldehyde-3-phosphate dehydrogenase (GAPDH; Hs02758991_g1; all from Life Technologies Corporation) and TaqMan Gene Expression Master Mix (Life Technologies Corporation) on a 7900HT PCR system (Life Technologies Corporation). The transcript levels of target genes were normalized to the corresponding GAPDH transcript levels. All values represent the results of at least three independent experiments. TissueScan Prostate Cancer Tissue qPCR array III (HPRT303), which contains first-strand cDNAs prepared from 48 human prostate tissues, including both malignant and healthy controls, was purchased from OriGene Technologies, Inc. (Rockville, MD, USA).

\section{Western blot analysis}

Whole-cell extracts were prepared as described previously (Shiota et al. 2010, 2011a, 2012b). Briefly, the concentration of the prepared protein extracts was quantified using a Protein Assay (Bio-Rad Laboratories) based on the Bradford method. Aliquots (30 $\mu$ g protein) were separated by $4-20 \%$ SDS-PAGE and transferred to PVDF microporous membranes (GE Healthcare Bio-Sciences Corporation, Piscataway, NJ, USA) using a semi-dry blotter. The membranes were then incubated with the primary antibodies described previously for $1 \mathrm{~h}$ at room temperature, followed by incubation with peroxidase-conjugated secondary antibodies for $40 \mathrm{~min}$ at room temperature. The bound antibodies were visualized using an ECL kit (GE Healthcare Bio-Sciences Corporation), and images were obtained using an image analyzer (Ez-Capture MG, ATTO, Tokyo, Japan).

\section{Cell invasion assay}

Cell invasion assay was performed as described previously (Shiota et al. 2013b). Briefly, cell invasion was performed using $8-\mu \mathrm{m}$ pore matrigel invasion chambers (BD Biosciences). Prostate cancer cells $\left(5 \times 10^{4}\right)$ were deposited in the upper chamber with $500 \mu \mathrm{l}$ of serum-free medium, and the lower compartment was filled in $500 \mu \mathrm{l}$ of media with $10 \%$ FBS. After incubation for $24 \mathrm{~h}$, non-invaded cells on the upper surface of the filter were carefully removed with a cotton swab, and cells were fixed with $100 \%$ methanol for $2 \mathrm{~min}$. Invading cells on the lower side of the filter were stained with $0.5 \%$ crystal violet for $5 \mathrm{~min}$, and the dye was eluted with Sorensen's solution ( $30 \mathrm{mM}$ sodium citrate, $0.02 \mathrm{M} \mathrm{HCl}$ and $50 \%$ ethanol) and optical density (OD) was measurement at a wavelength of $595 \mathrm{~nm}$. The results are representative of at least three independent experiments.

\section{Cytotoxicity analysis}

Cytotoxicity analysis was performed as described previously (Shiota et al. 2012c). Briefly, prostate cancer cells $\left(2.5 \times 10^{3}\right)$ were seeded in 96 -well plates. On the following day, media was changed to CSS-media with or without $1 \mathrm{nM}$ of DHT. After $72 \mathrm{~h}$, the surviving cells were stained using the alamarBlue assay (TREK Diagnostic Systems, Inc., Cleveland, $\mathrm{OH}, \mathrm{USA}$ ) at $37^{\circ} \mathrm{C}$ for $180 \mathrm{~min}$. The absorbance of each well was measured using an ARVO MX plate reader (Perkin Elmer, Inc., Waltham, MA, USA). The results are representative of at least three independent experiments.

\section{Immunohistochemistry}

Immunohistochemical staining was performed as previously described (Imada et al. 2013). Briefly, the

Published by Bioscientifica Ltd. 

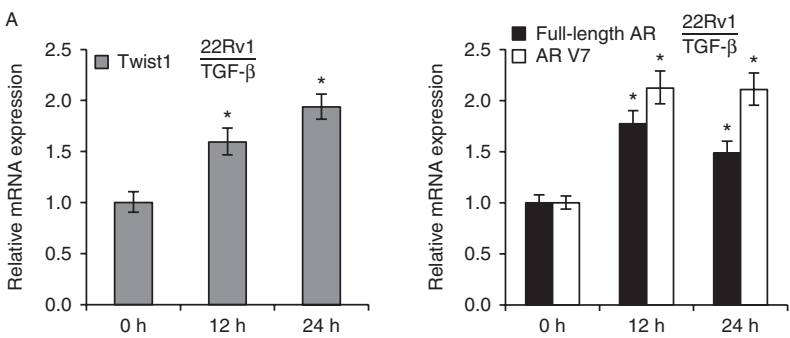

B
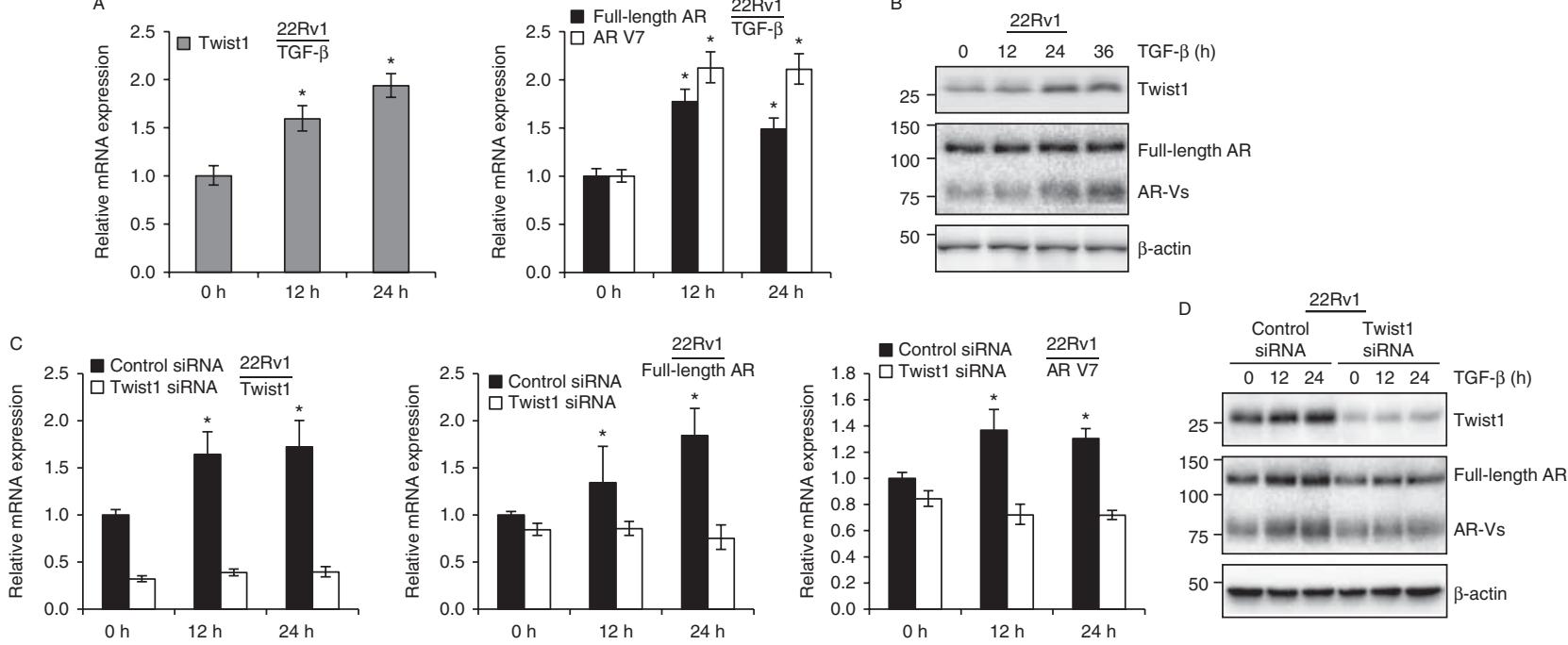

Figure 1

TGF- $\beta$ induces AR expression via Twist 1 transcription factor. ( $A$ and $B$ ) $22 R v 1$ cells were treated with $5 \mathrm{ng} / \mathrm{ml} \mathrm{TGF}-\beta$ for the indicated duration. (A) qRT-PCR was conducted using the primer pairs and probes for Twist1, full-length $A R, A R V 7$, and GAPDH. Each transcript level from non-treated cells was set as 1 . Boxes, mean; bars \pm s.D.; ${ }^{*} P<0.05$ (compared with no treatment). (B) Whole-cell extracts were analyzed by SDS-PAGE and western blot analysis with specified antibodies. ( $C$ and D) 22Rv1 cells were

EnVision Plus detection system (DAKO, Glostrup, Denmark), with the primary antibodies against AR (N-20; 1:100) and Twist1 (T6451 from Sigma-Aldrich; 1:200) were used. Four micrometer-thick sections from 10\% formalin-fixed paraffin embedded material were deparaffinized in xylene and rehydrated with ethanol. Endogenous peroxidase activity was blocked for $30 \mathrm{~min}$ using methanol containing $0.3 \%$ hydrogen peroxidase. Antigen retrieval was performed by microwave heating for $20 \mathrm{~min}$ with Target Retrieval Solution (pH 9.0; DAKO). Next, the sections were incubated at $4{ }^{\circ} \mathrm{C}$ overnight with the primary antibody, followed by staining for $40 \mathrm{~min}$ with the secondary antibody/peroxidase-linked polymers (EnVision +; DAKO) at room temperature. The reaction products were visualized by diaminobenzidine tetrahydrochloride as a chromogen. Finally, the sections were counterstained with hematoxylin.

\section{Immunohistochemical analysis}

AR nuclear expression was assessed by counting the stained nuclei from at least 1000 tumor cells, selected from the areas of greatest accumulation of positive signals (hotspots). For scoring Twist1 expression, we assessed the proportion of stained cells divided into five categories transfected with $40 \mathrm{nmol} / \mathrm{l}$ of the indicated siRNA and incubated for $24 \mathrm{~h}$, and cells were treated with $5 \mathrm{ng} / \mathrm{ml}$ of TGF- $\beta$ for the indicated durations. (C) qRT-PCR was conducted using the primer pairs and probes for Twist1, full-length $A R, A R V 7$, and GAPDH. Each transcript level from non-treated cells was set as 1 . Boxes, mean; bars \pm s.D.; $* P<0.05$ (compared with no treatment). (D) Whole-cell extracts were analyzed by SDS-PAGE and western blot analysis with specified antibodies.

as follows: 0 , completely negative; $1,1-25 \% ; 2,26-50 \%$; 3, 51-75\%; 4, 76-100\%. Staining intensity was divided into four categories as follows: 0, negative; 1, weak; 2 , moderate; 3 , strong. The proportion and intensity scores were then multiplied to obtain a total score $(\mathrm{Chu}$ et al. 2012).

\section{In vivo tumor model}

Xenograft experiments in mice were performed as previously described (Shiota et al. 2012b). Briefly, to obtain LNCaP xenograft tumors, LNCaP cells $\left(5 \times 10^{7}\right)$ with $0.1 \mathrm{ml}$ matrigel (BD Biosciences) were inoculated in the flank of 6- to 8-week-old male athymic nude mice. Castration was conducted when tumor volume reached more than $100 \mathrm{~mm}^{3}$. At the time when tumor volume reached to over $1000 \mathrm{~mm}^{3}$ with castration (CRPC tumors, $n=5$ ) or without castration (naïve tumors, $n=3$ ), xenografts were harvested and then analyzed. To examine the effect of castration and TGF- $\beta$ inhibitor SB525334 on 22Rv1 tumor growth, 22Rv1 cells $\left(3 \times 10^{6}\right)$ with $0.1 \mathrm{ml}$ matrigel (BD Biosciences) were inoculated in the flank of 6- to 8 -week-old male athymic nude mice. The following day, mice were then randomly divided into four groups for treatment with castration and/or SB525334.

Published by Bioscientifica Ltd. 
Each experimental group consisted of eight mice. After randomization, castration was conducted and SB525334 at a dose of $200 \mathrm{mg} / \mathrm{l}$ drinking water was started to be given every day as previously shown (Laping et al. 2007) at 2 weeks after inoculation. Then, tumor size in mice was measured weekly.

Tumor volume was measured using calipers. Tumor volume was calculated using the formula $\mathrm{V}=\left(\mathrm{A} \times \mathrm{B}^{2}\right) / 2$, where $V$ is the volume $\left(\mathrm{mm}^{3}\right)$, and $A$ and $B$ is the long and short diameter of the tumor $(\mathrm{mm})$ respectively. Animals were maintained and handled according to the Japanese government and institutional guidelines. The protocol was approved by the institutional committee.

\section{Statistical analysis}

All data were assessed using the Student's $t$-test and $\chi^{2}$ test. Levels of statistical significance were set at $P<0.05$.

\section{Results}

\section{Twist1 mediates TGF- $\beta$-induced expression of both full-length and splice-variant AR expression}

Because TGF- $\beta$ is a well-known EMT inducer, we examined the effect of TGF- $\beta$ on this transition process. 22Rv1 cells are known to express both extra-long full-length and C-terminal-deleted splice-variants of AR (AR V7, also termed AR3) which are both detected by anti-AR antibody $(\mathrm{N}-20)$ recognizing $\mathrm{N}$-terminus of $\mathrm{AR}$ protein and its growth is androgen sensitive (Dehm et al. 2008, Li et al. 2011). In addition, $22 \mathrm{Rv} 1$ cells express the receptor for TGF- $\beta$ and respond to TGF- $\beta$, while another representative AR-expressing prostate cancer cell line (LNCaP) is null for the TGF- $\beta$ receptor (TGF- $\beta$ R2). We have previously shown that Twist 1 expression was induced and EMT markers were deregulated by exogenous administration of TGF- $\beta$ in 22Rv1 cells (Shiota et al. 2012a).

22Rv1 cells were used as model AR-expressing prostate cancer cells for assessing the effects of TGF- $\beta$ exposure. First, we examined Twist1 and $A R$ transcript levels after TGF- $\beta$ stimulation. As shown in Fig. 1a, Twist 1 and both full-length and splice-variant transcript forms of $A R$ were induced by TGF- $\beta$ stimulation in a time-dependent manner. Similarly, at the protein level, the expression of Twist1 and both full-length (upper band) and splice variants of AR (lower band) were induced by exposure to TGF- $\beta$ (Fig. 1b).

To delineate the role of the Twist 1 transcription factor in AR induction by TGF- $\beta$, the effect of Twist 1 silencing on
AR induction by TGF- $\beta$ was examined. As shown in Fig. 1c, Twist1 silencing using Twist1-specific siRNA abolished the TGF- $\beta$-induced up-regulation of Twist1 as well as the production of both full-length and splice-variant $A R$ transcripts. In addition, Twist1 knockdown suppressed AR expression of both full-length and splice-variant forms at the protein level (Fig. 1d).

Furthermore, to examine long-term effects of TGF- $\beta$ exposure, we established 22Rv1/TGF derivative from parental 22Rv1 cells by incubating these cells for more than 3 months with TGF- $\beta$. As expected, 22Rv1/TGF cells expressed more abundant Twist1 as well as both fulllength and splice-variant AR proteins, accompanied by the induction of the mesenchymal makers N-cadherin, fibronectin, and vimentin. However, expression of the epithelial marker E-cadherin remained constant (Fig. 2a). Moreover, 22Rv1/TGF cells exhibited more invasive ability compared with parental 22Rv1 cells (Fig. 2b). Finally, consistent with overexpressed AR, 22Rv1/TGF cells proliferated in a castration-resistant manner (Fig. 2c).
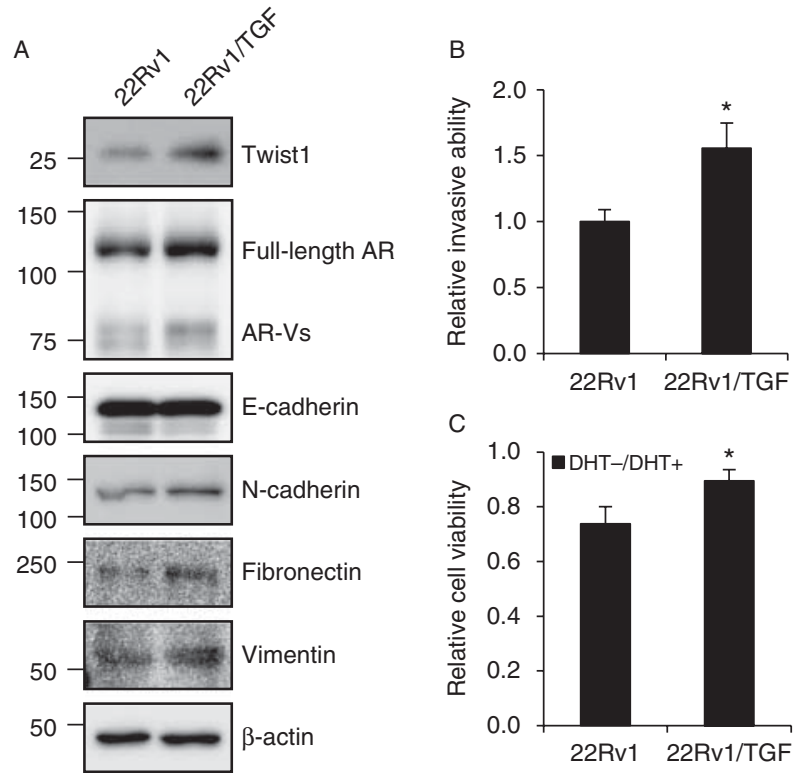

\section{Figure 2}

Long-term TGF- $\beta$ exposure induces EMT characteristics and AR expression. (A) Whole-cell extracts from 22Rv1 and 22Rv1/TGF cells were analyzed by SDS-PAGE and western blot analysis with specified antibodies. (B) Invasion assay was conducted using $22 \mathrm{Rv} 1$ and $22 \mathrm{Rv} 1 / \mathrm{TGF}$ cells. The invasive cell count of $22 \mathrm{Rv} 1$ cells was set as 1 . Boxes, mean; bars \pm s.D.; $* P<0.05$ (compared with 22Rv1 cells). (C) 22Rv1 and 22Rv1/TGF cells were seeded in 96-well plates. On the following day, media was changed to CSS-media with or without $1 \mathrm{nM}$ of DHT. After $72 \mathrm{~h}$, cell survival rates were analyzed by cytotoxicity analyses. Boxes, mean; bars \pm s.D. ${ }^{\star} P<0.05$ (compared with 22Rv1 cells).

Published by Bioscientifica Ltd. 


\section{Highly invasive clone shows augmented AR signaling accompanied by a castration-resistant phenotype}

Based on the results of highly invasive 22Rv1/TGF cells, we attempted to delineate the crosstalk between EMT and castration resistance using a highly invasive cell model. First, we established a highly invasive 22Rv1/HI clone from parental 22Rv1 cells; 22Rv1/HI cells exerted higher invasive ability compared with parental 22Rv1 cells (Fig. 3a).

We also compared the transcript levels of Twist1 and $A R$ between the parental cell line and the invasive clone. As shown in Fig. 3b, transcript expression of Twist1, as well as both full-length and splice variants of $A R$, were up-regulated in 22Rv1/HI cells compared with parental 22Rv1 cells (Fig. 3b). In addition, similar results were obtained at the protein level (Fig. 3c). Furthermore, expression of the epithelial marker E-cadherin decreased, while mesenchymal markers N-cadherin, fibronectin, and vimentin were elevated in 22Rv1/HI cells (Fig. 3c). Consistent with increased AR expression, 22Rv1/HI cells grew well even in androgen-free conditions compared with under androgen-supplemented conditions, indicating that $22 \mathrm{Rv} 1 / \mathrm{HI}$ cells have a castration-resistant phenotype (Fig. 3d).

\section{AR and EMT signaling is activated in castration-resistant tumors}

We aimed to examine AR and EMT signaling in castration-resistant tumors. For this objective, we used LNCaP-xenograft mouse model because LNCaP cells are a well-established and almost only castration-sensitive prostate cancer model although LNCaP cells harbor mutated AR (T877A). As shown in Fig. 4a, Twist1 and both full-length and splice-variant $A R$ transcript levels were up-regulated in CRPC tumors compared with ADTnaïve tumors. In addition, the mesenchymal markers fibronectin and vimentin were similarly elevated (Fig. 4a); similar results at the protein level were also confirmed, as shown in Fig. 4b. Intriguingly, AR expression was different between when culture in vitro and inoculated in vivo, which may be accounted for by the environmental difference (Fig. 4b). Furthermore, immunohistochemical
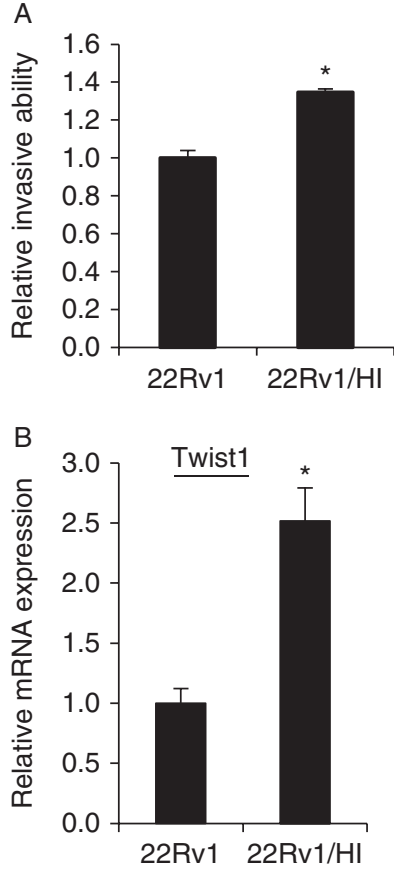
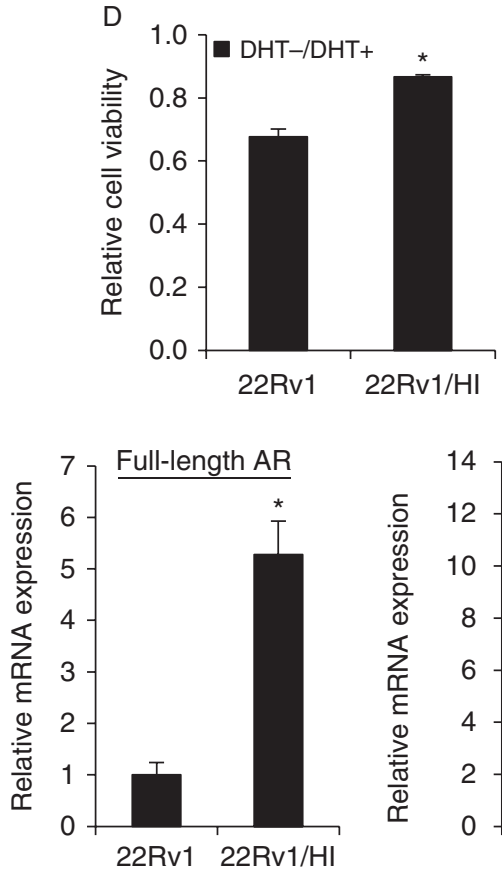
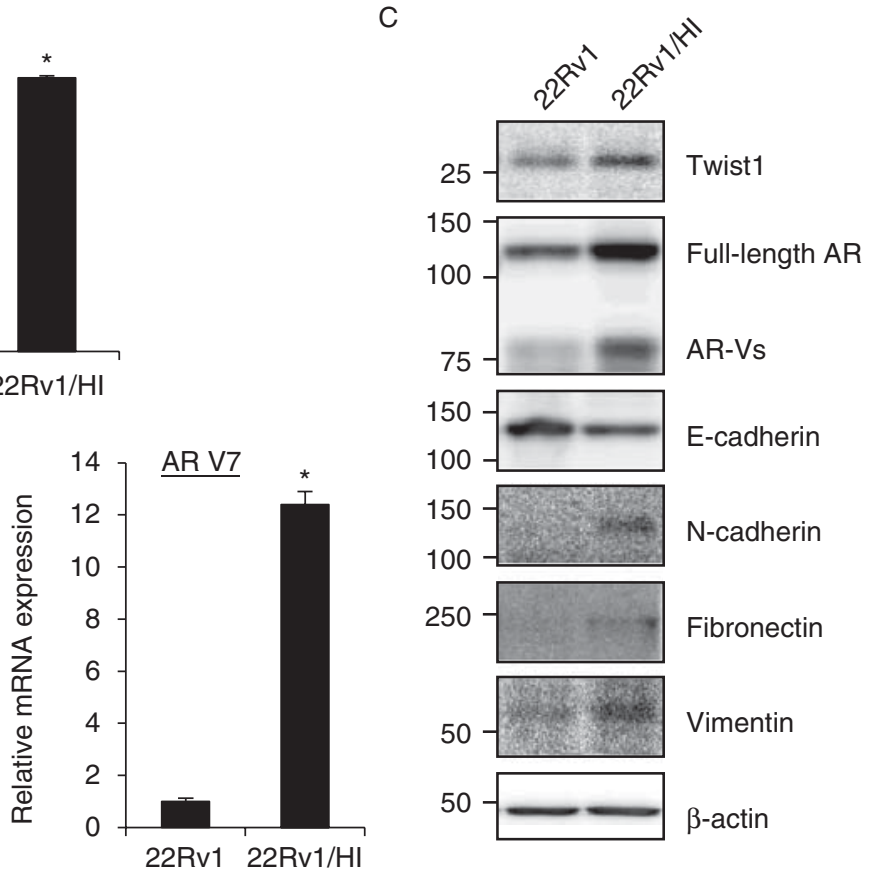

Figure 3

The highly invasive clone shows augmented AR signaling accompanied by a castration-resistant phenotype. (A) Invasion assay was conducted using the indicated cells. The invasive cell count of $22 \mathrm{Rv} 1$ was set as 1 . Boxes, mean; bars \pm s.D.; ${ }^{*} P<0.05$ (compared with $22 \mathrm{Rv} 1$ cells). (B) After extraction of total RNA from the indicated cells and CDNA synthesis, qRT-PCR was conducted using the primer pairs and probes for Twist1, full-length $A R$, $A R V 7$, and GAPDH. Each transcript level from non-treated cells was set as 1 .

Boxes, mean; bars +s.D.; * $P<0.05$ (compared with 22Rv1 cells). (C) Whole-cell extracts from the indicated cells were analyzed by SDS-PAGE and western blot analysis with specified antibodies. (D) 22Rv1 and 22Rv1/HI cells were seeded on 96-well plates. On the following day, media was changed to CSS-media with or without $1 \mathrm{nM}$ of DHT. After $72 \mathrm{~h}$, cell survival rates were analyzed by cytotoxicity analyses. Boxes, mean; bars \pm s.D. * $P<0.05$ (compared with 22Rv1 cells). 

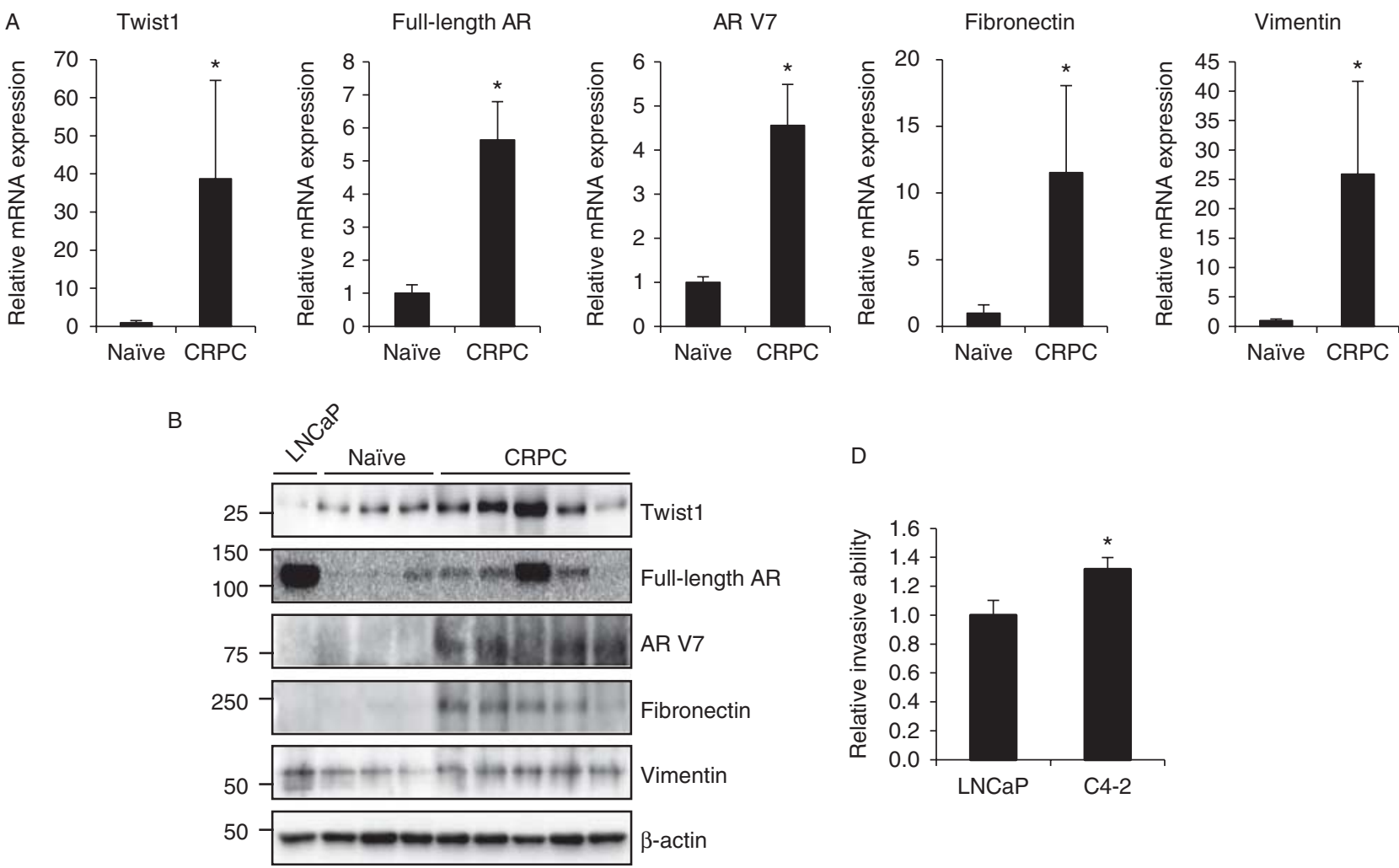

C

Naïve

CRPC
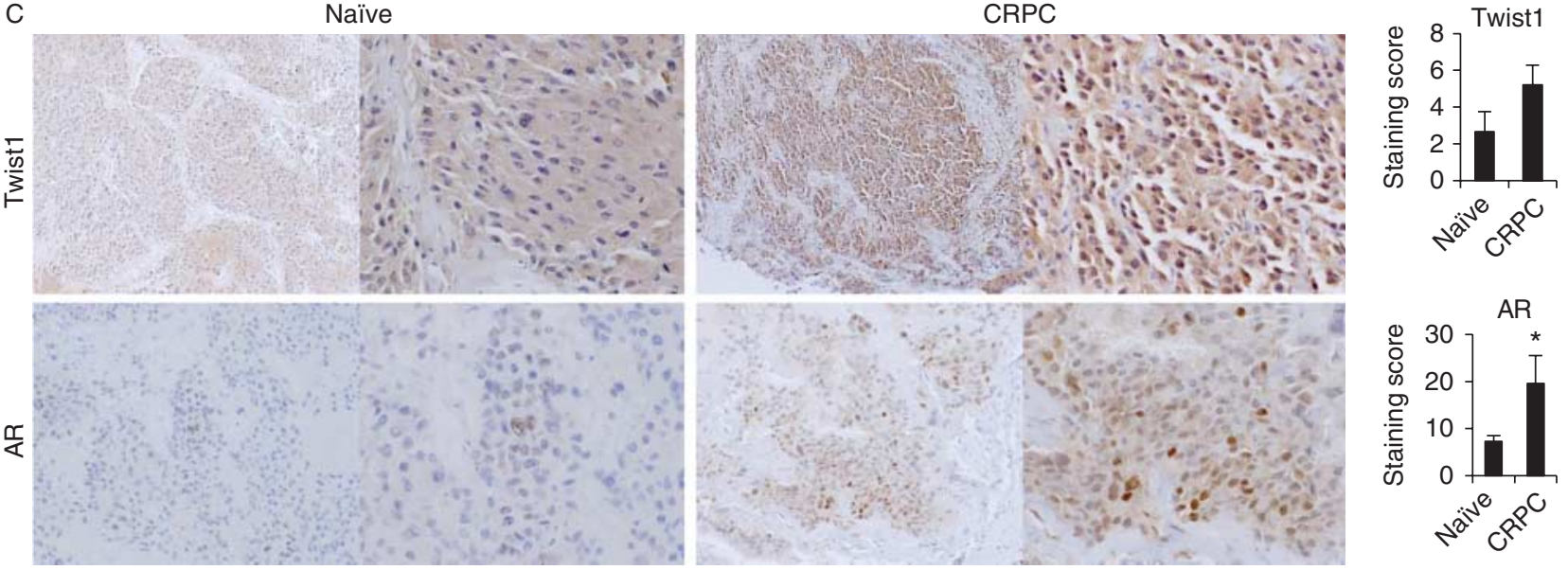

Figure 4

AR as well as EMTsignaling is activated in castration-resistant tumors. (A) After extraction of total RNA from the indicated tumors and CDNA synthesis, qRTPCR was conducted using the primer pairs and probes for Twist1, full-length $A R, A R V 7$, fibronectin, vimentin, and GAPDH. Each transcript level from nontreated cells was set as 1. Boxes, mean; bars \pm s.D.; ${ }^{*} P<0.05$ (compared with naïve tumor). (B) Extracts from the indicated tumors were analyzed by SDS-PAGE and western blot analysis with specified antibodies.

staining showed that increased Twist 1 and AR expression was evident in CRPC tumors compared with ADT-naïve tumors (Fig. 4c). Moreover, the positive rate of Twist1 nuclear staining was higher in CRPC tumors (40\%)
(C) Immunohistochemistry against the indicated antibodies in naïve and CRPC tumors is shown. The graphs indicate the score of staining intensity in each tumor. Boxes, mean; bars \pm s.D.; ${ }^{*} P<0.05$ (compared with naïve tumor). (D) Invasion assay was conducted using the indicated cells as described in Materials and methods. The invasive cell count of LNCaP was set as 1 . Boxes, mean; bars \pm s.D.; $* P<0.05$ (compared with $\mathrm{LNCaP}$ cells). A full colour version of this figure is available at http://dx.doi.org/10.1530/ERC-15-0225.

compared with ADT-naïve tumors ( $0 \%)$. To compare the invasive ability between androgen-dependent cells and castration-resistant cells, we performed invasion assays using LNCaP cells and its castration-resistant derivative, 
C4-2 cells. As shown in Fig. 4d, the invasive ability of C4-2 cells was higher than LNCaP cells.

\section{Twist1 and $A R$ transcript expression in human prostate cancer tissues}

We examined Twist1 and AR expression in human prostate tissues using tissue arrays containing cDNA from nine normal prostatic tissues and 39 prostate cancer tissues, including 18 tissues with pT2 tumors and 21 tissues with pT3 tumors. The result showed that both Twist1 $(P=0.0089)$ and $A R(P=0.090)$ transcript expression were elevated in prostate cancer tissues compared with normal prostatic tissues (Fig. 5a), indicating the biological relevance of Twist1/AR signaling in human prostate tissues.

In addition, full-length $A R$ transcript expression was elevated in tumors with extraprostatic extension (pT3) compared with organ-confined tumors (pT2), as shown in Fig. 5b. Similarly, splice-variant $A R$ transcript expression was higher in extraprostatic-extension tumors compared with organ-confined tumors ( $P=0.029$; Fig. $5 b)$.
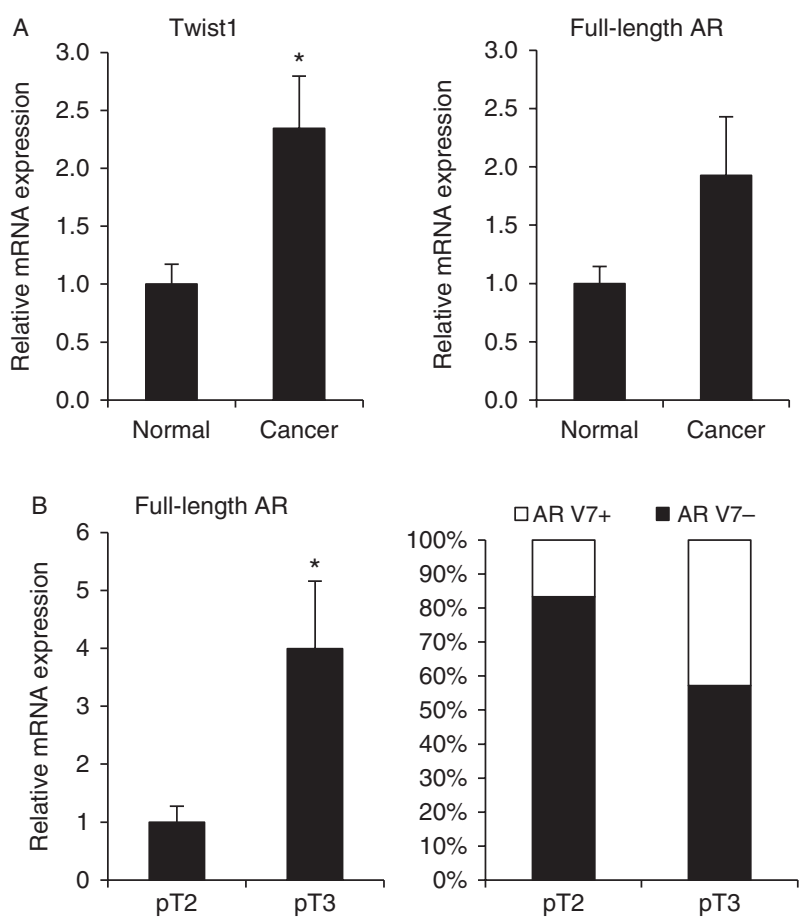

Figure 5

Twsit1 and $A R$ transcript expression in human prostate cancer tissues. (A and $\mathrm{B}$ ) Twsit1, full-length $A R, A R V 7$, and GAPDH expression in normal prostate and prostate cancer CDNA was determined. The graphs indicate relative expression of the indicated gene (A, normal vs cancer; $B, p T 2$ vs pT3). For $A R V 7$, positive expression was compared with negative expression between pT2 and pT3. Boxes, mean; bars \pm s.D.; ${ }^{*} P 0.05$ (compared with normal tissue or pT2).
TGF- $\beta$ inhibitor suppresses Twist 1 and AR expression as well as prostate cancer proliferation

To investigate the effect of inhibiting TGF- $\beta$ signal, we utilized small molecule TGF- $\beta$ inhibitor SB525334. Then, the expression levels of Twist1 and AR were examined. Although Twist1 as well as both full-length $A R$ and $A R V 7$ expression at transcript level was induced by TGF- $\beta$, TGF- $\beta$ inhibitor SB525334 abolished the inductions of Twist1 as well as both full-length $A R$ and $A R V 7$ transcripts (Fig. 6a). Consistently, similar result was obtained also at protein level (Fig. 6b). In addition, TGF- $\beta$ inhibitor SB525334 suppressed the augmented cell proliferation by TGF- $\beta$ although unaffected cell proliferation without TGF- $\beta$ (Fig. 6c).

Finally, we examined the effect of TGF- $\beta$ inhibitor SB525334 combined with or without castration on in vivo tumor growth. The result showed that TGF- $\beta$ inhibitor SB525334 significantly combined with castration suppressed 22Rv1 tumor growth most effectively although castration alone marginally suppressed tumor growth (Fig. 6d). Consistently, phosphorylated Smad2/3 levels in tumors were augmented by castration alone although blunted with SB525334 treatment (Fig. 6e). On the other hand, body weight was constant during 4 weeks of treatment was constant among each arm, suggesting no apparent adverse effect of therapeutics even when combined (Fig. 6f).

\section{Discussion}

It is well known that clinically high-burden prostate tumors with evidence of invasion and multiple metastases represented by high TNM stage are more likely to become castration resistant (Cooperberg et al. 2009). It was also reported that CTC counts increased according to castration-resistant progression after suppression by ADT (Danila et al. 2011, Miyamoto et al. 2012), suggesting that CRPC may have higher metastatic potential compared with androgen-dependent prostate cancer cells by disseminating cancer cells systemically. However, it remains unclear why advanced prostate cancer with metastases more easily becomes castration resistant and vice versa.

Previously, we and others have shown that the EMTinducing factor TGF- $\beta$ up-regulated Twist 1 transcription factor in PC-3 and 22Rv1 cells (Shah \& Kakar 2011, Shiota et al. 2012a). Conversely, we have reported that Twist1 regulated AR expression in LNCaP and 22Rv1 cells (Shiota et al. 2010), suggesting that the contribution of Twist1 to castration resistance through augmented AR signaling. Therefore, we speculated that AR expression might be

Published by Bioscientifica Ltd. 

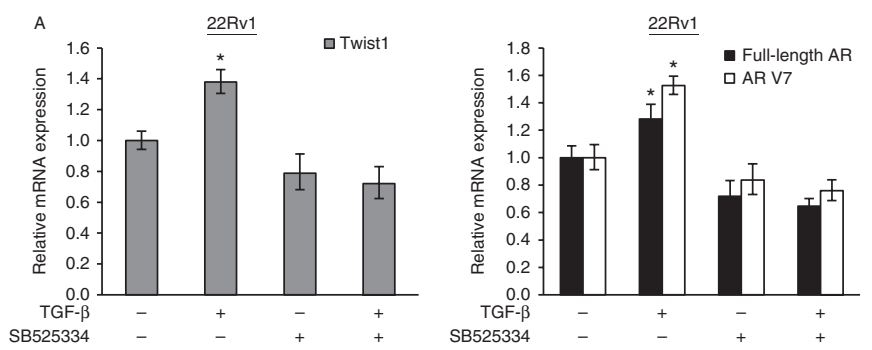
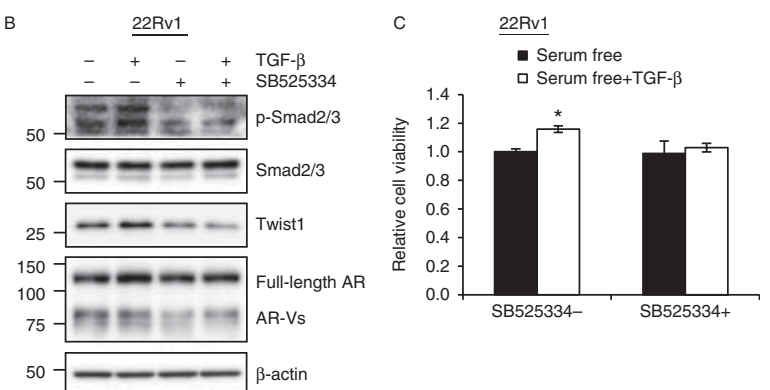

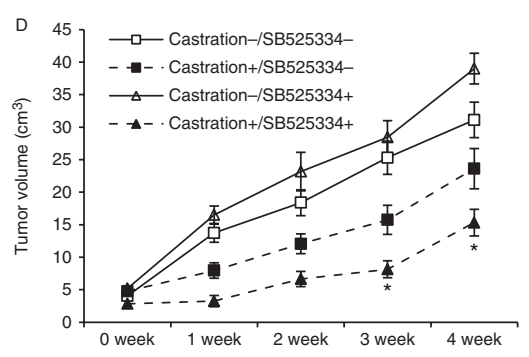

Figure 6

TGF- $\beta$ inhibitor suppresses Twist 1 and AR expression as well as prostate cancer proliferation. ( $A$ and B) $22 \mathrm{Rv} 1$ cells were treated with $5 \mathrm{ng} / \mathrm{ml} \mathrm{TGF}-\beta$ and/or $5 \mu \mathrm{M}$ SB525334 for $24 \mathrm{~h}$. (A) qRT-PCR was conducted using the primer pairs and probes for Twist1, full-length $A R, A R V 7$, and GAPDH. Each transcript level from non-treated cells was set as 1. Boxes, mean; bars \pm s.D.; ${ }^{*} P<0.05$ (compared with no treatment). (B) Whole-cell extracts were analyzed by SDS-PAGE and western blot analysis with specified antibodies. (C) 22Rv1 cells were seeded in 96-well plates. On the following day, media was changed to serum-free media with or without $5 \mathrm{ng} / \mathrm{ml} \mathrm{TGF-} \beta$ and/or $5 \mu \mathrm{M}$ SB525334. After $48 \mathrm{~h}$, cell survival rates were analyzed by cytotoxicity

induced by TGF- $\beta$ stimulation via the Twist 1 transcription factor. As expected, short- and long-term stimulation with TGF- $\beta$ induced Twist1 and AR expression in 22Rv1 cells, accompanied by a mesenchymal phenotype as represented by increased expression of mesenchymal markers and increased invasive ability. Taken together, these findings suggest that TGF- $\beta$ induces a mesenchymal phenotype and augments AR signaling through the Twist1 transcription factor thereby promoting castration resistance, which is indicative of a close link between EMT and castration resistance (Fig. 7). Consistent with our current findings, it has previously been reported that TGF- $\beta$ and AR signaling mutually promoted their respective signals in PC-3 and $\mathrm{LNCaP}$ cells in which AR and TGF- $\beta$ R2 are overexpressed (Zhu et al. 2008). However, in classical TGF- $\beta$-induced pathway activation, Smad3/4 functions as both an AR co-activator and co-repressor, suggesting a complex role for Smad3/4 pathway in regulating AR signaling (Kang et al. 2002).

Concerning the biological role of TGF- $\beta$ in prostate cancer, it has been shown that signaling by bone morphogenetic proteins (BMPs), belonging to the TGF- $\beta$ superfamily, play pivotal roles in bone metastasis analyses. Boxes, mean; bars \pm s.D. ${ }^{\star} P<0.05$ (compared with no treatment). (D) 22Rv1 cells were inoculated subcutaneously into the lateral flank of mice. The following day, mice were randomly divided into four groups, and treatment with or without castration and SB525334 was started. The sizes of primary tumors were determined every week using calipers. Tumor growth in mice xenograft is shown. Boxes, mean; bars \pm s.E.M.; $* P<0.05$ (compared with no treatment). (E) The extracts from randomly selected tumors analyzed by SDS-PAGE and western blot analysis with specified antibodies. (F) Body weight in mice treated with castration and/or SB525334 for 4 weeks is shown. Boxes, mean; bars \pm S.E.M.

(Ye et al. 2011), which is one of the most common and severe complications of prostate cancer. Based on the findings in this study, BMPs, like TGF- $\beta$, in bones might promote EMT as well as castration resistance in bone-metastatic prostate cancer, which is reflected in the clinical finding that prostate cancer with multiple bone metastasis frequently and rapidly becomes castration resistant (Cooperberg et al. 2009).

In this study, we examined the status of AR signaling and castration resistance using cells with high EMT characteristics, which share the same characteristics as cells in the presence of TGF- $\beta$. To develop the experimental model, we established a clone of highly invasive cells by matrigel invasion selection (Jacob et al. 1995). The selected clone (22Rv1/HI cells) exhibited mesenchymal characteristics manifested by high invasiveness as well as decreased epithelial markers and increased mesenchymal makers concurrent with increased expression of Twist 1 as well as both full-length and splice-variant forms of AR. Based on augmented AR expression in $22 \mathrm{Rv} 1$ cells, castration resistance was promoted in 22Rv1/HI cells, suggesting that a highly invasive clone with a mesenchymal phenotype easily developed castration resistance

Published by Bioscientifica Ltd 


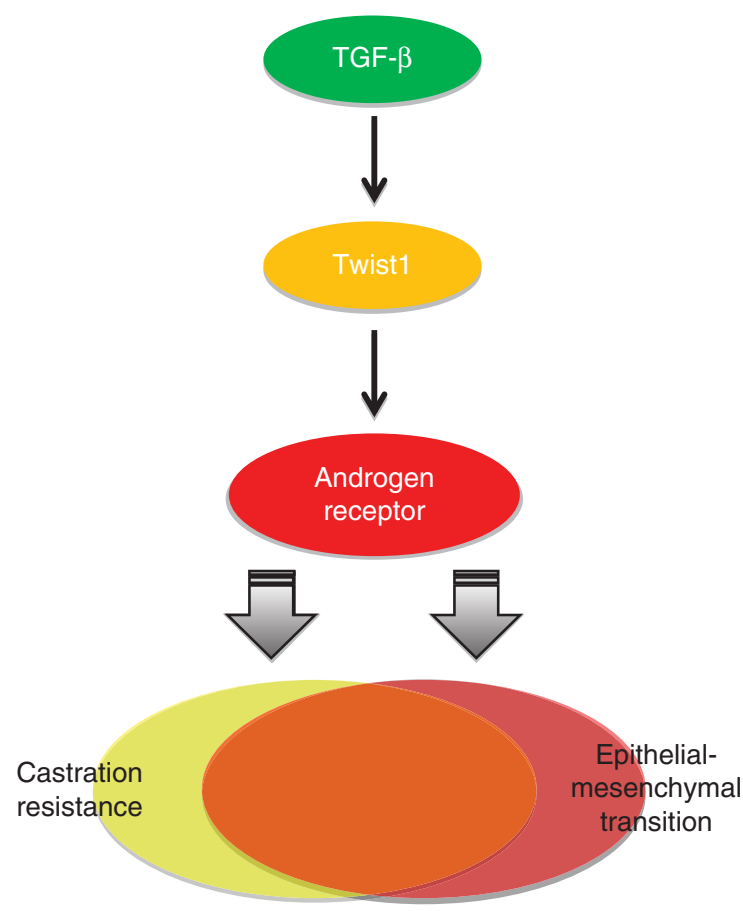

Figure 7

Schematic representation of crosstalk between EMT and castration resistance revealed in this study. A full colour version of this figure is available at http://dx.doi.org/10.1530/ERC-15-0225.

in an experimental model. Our results corroborate a previous study in which highly invasive clones from androgen-dependent prostate cancer cells expressed higher levels of AR (Hara et al. 2008).

Conversely, several studies have proposed AR overexpression in prostate cancer as a mechanism for the progression to castration resistance after androgen deprivation (Shiota et al. 2011b). As well, TGF- $\beta 1$ expression was also shown to be induced by androgen deprivation in human prostatic tissues (Fuzio et al. 2012). We and others have shown that the EMT-regulating transcription factor Twist1 was induced by androgen deprivation (Shiota et al. 2012b, Sun et al. 2012). Furthermore, CRPC tumors from LNCaP-xenograft model using castrated mice showed augmented AR signaling as well as an EMT phenotype, characterized by increased expression of Twist 1 as well as other mesenchymal markers. These findings indicate that the development of castration resistance occurs after androgen deprivation induced EMT (Fig. 7), which leads to more aggressive characteristics, such as high invasion and metastasis as well as possible resistance to anticancer treatment by cytotoxic agents, including taxanes, resulting in critical, terminal illness (Shiota et al. 2013a).
Recently, TGF- $\beta$ was suggested to play a critical role not only in prostate tumor progression, but also prostate carcinogenesis (Franco et al. 2011). In fact, TGF- $\beta$ levels in urine were elevated in prostate cancer patients compared with normal controls (Perry et al. 1997), although the same pattern was not observed with respect to serum levels (Wolff et al. 1998). In this study, we showed elevated Twist 1 and AR expression, which are induced by TGF- $\beta$, in prostate cancer tissues compared with normal prostatic tissues. Consistent with this result, Twist1 was previously shown to be up-regulated in prostate cancer compared with normal prostatic tissue (Kwok et al. 2005), in addition to the well-known roles of AR in prostatic carcinogenesis. Accordingly, Twist1/AR signaling was suggested to play a critical role not only in human prostate cancer progression, but also in prostate carcinogenesis.

Accumulating evidence has recently emerged supporting the role of deregulated AR in promoting the EMT process. In androgen-dependent prostate cancer cells, AR signaling increased invasive ability by mediating metalloproteinase and TMPRESS2 activities (Lucas et al. 2014). Furthermore, activated AR stimulated $\beta$-catenin and suppressed E-cadherin gene expression in prostate cancer cells, resulted in an induction of mesenchymal-like cell morphology (Liu et al. 2008, Zhu \& Kyprianou 2010). It has recently been reported that AR splice variants dominantly regulate the expression of the mesenchymal marker N-cadherin (Cottard et al. 2013). The present study showed that CRPC tumors in which AR expression was elevated showed mesenchymal characteristics manifested by increased expression of mesenchymal markers, suggesting that CRPC tumors may have highly invasive and metastatic potential. This is supported by a recent report showing that $\mathrm{N}$-cadherin is up-regulated in CRPC tissues (Tanaka et al. 2010). As shown in this study, AR expression was elevated in invasive prostate cancer, which is consistent with a previous report showing that higher levels of AR expression is correlated with extraprostatic extension, seminal vesicle invasion, and lymph-node involvement in radical prostatectomy specimens (Li et al. 2004). Collectively, the findings revealed in this study have suggested the hypothesis that an inhibition of EMT signaling induced by blocking AR signaling would lead to the eradication of compensated augmentation of $\mathrm{AR}$ signaling as well as castration resistance. Actually, reversed EMT signaling by TGF- $\beta$ inhibitor suppressed Twist 1 and $\mathrm{AR}$ expression as well as tumor growth combined with castration probably due to an inhibition of castration resistance. This result is consistent with the previous

Published by Bioscientifica Ltd 
reports that TGF- $\beta$ inhibitor restored chemo-sensitivity to paclitaxel (Bhola et al. 2013) and radio-sensitivity in breast cancer (Bouquet et al. 2011). This study has successfully shown that TGF- $\beta$ receptor inhibitor SB525334 could suppress tumor growth of $22 \mathrm{Rv} 1$ cells specifically in combination with castration although SB52334 alone did not. This result indicates that TGF- $\beta$-targeting therapy may be a favorable combination with ADT in prostate cancer by inhibiting EMT as well as the development of castration resistance as shown in Fig. 7.

In conclusion, this study revealed that TGF- $\beta$ induced mesenchymal conversion by increasing Twist1/AR signaling, and that clonal selection contributes to an EMT phenotype as well as augmented AR signaling, leading to castration resistance. Furthermore, we report that augmented Twist1/AR signaling in CRPC promotes EMT. Taken together, these results revealed the molecular mechanism of close mutual and functional crosstalk between EMT and castration resistance mediated by Twist1/AR signaling, which may play a crucial role in prostate carcinogenesis and progression. Actually, dual inhibition of EMT and AR signaling coordinately suppressed tumor growth through coordinate inhibition of mechanisms for EMT and castration resistance. Thus, the identification of the crosstalk between EMT and castration resistance by Twist1/AR signaling offers the potential to develop novel strategies for overcoming progression and castration resistance in prostate cancer. The biological findings in this study also suggest that AR signaling in EMT during embryonic prostate genesis might be required and androgen deprivation might cause prostate cancer cells to migrate to distant locations to survive.

\section{Declaration of interest}

The authors declare that there is no conflict of interest that could be perceived as prejudicing the impartiality of the research reported.

\section{Funding}

This work was supported by Kakenhi grants (25462483, 25462484 and 26861273) from the Ministry of Education, Culture, Sports, Science, and Technology of Japan (MEXT), Japan; a Medical Research Promotion Grant from Takeda Science Foundation, Japan; and a Research Promotion Grant from the Uehara Memorial Foundation, Japan.

\section{Acknowledgements}

We are grateful to $\mathrm{Dr}$ Martin Gleave (Vancouver Prostate Centre, Vancouver, BC, Canada) for providing the C4-2 cells. We would like to thank Edanz Group Japan for editorial assistance, and Ms Noriko Hakoda and Ms Eriko Gunshima for technical assistance.

\section{References}

Ansieau S, Morel AP, Hinkal G, Bastid J \& Puisieux A 2010 TWISTing an embryonic transcription factor into an oncoprotein. Oncogene 29 3173-3184. (doi:10.1038/onc.2010.92)

Bhola NE, Balko JM, Dugger TC, Kuba MG, Sánchez V, Sanders M, Stanford J, Cook RS \& Arteaga CL 2013 TGF- $\beta$ inhibition enhances chemotherapy action against triple-negative breast cancer. Journal of Clinical Investigation 123 1348-1358. (doi:10.1172/JCI65416)

Bouquet F, Pal A, Pilones KA, Demaria S, Hann B, Akhurst RJ, Babb JS, Lonning SM, DeWyngaert JK, Formenti SC et al. 2011 TGF $\beta 1$ inhibition increases the radiosensitivity of breast cancer cells in vitro and promotes tumor control by radiation in vivo. Clinical Cancer Research 17 6754-6765. (doi:10.1158/1078-0432.CCR-11-0544)

Chen Y, Sawyers CL \& Scher HI 2008 Targeting the androgen receptor pathway in prostate cancer. Current Opinion in Pharmacology 8 440-448. (doi:10.1016/j.coph.2008.07.005)

Chu XY, Zhu ZM, Chen LB, Wang JH, Su QS, Yang JR, Lin Y, Xue LJ, Liu XB $\&$ Mo XB 2012 FOXM1 expression correlates with tumor invasion and a poor prognosis of colorectal cancer. Acta Histochemica 114 755-762. (doi:10.1016/j.acthis.2012.01.002)

Cooperberg MR, Hinotsu S, Namiki M, Ito K, Broering J, Carroll PR \& Akaza H 2009 Risk assessment among prostate cancer patients receiving primary androgen deprivation therapy. Journal of Clinical Oncology 27 4306-4313. (doi:10.1200/JCO.2008.21.5228)

Cottard F, Asmane I, Erdmann E, Bergerat JP, Kurtz JE \& Céraline J 2013 Constitutively active androgen receptor variants upregulate expression of mesenchymal markers in prostate cancer cells. PLoS ONE 8 e63466. (doi:10.1371/journal.pone.0063466)

Danila DC, Fleisher M \& Scher HI 2011 Circulating tumor cells as biomarkers in prostate cancer. Clinical Cancer Research 17 3903-3912. (doi:10.1158/1078-0432.CCR-10-2650)

Dehm SM, Schmidt LJ, Heemers HV, Vessella RL \& Tindall DJ 2008 Splicing of a novel androgen receptor exon generates a constitutively active androgen receptor that mediates prostate cancer therapy resistance. Cancer Research 68 5469-5477. (doi:10.1158/0008-5472.CAN-08-0594)

Franco OE, Jiang M, Strand DW, PeacockJ, Fernandez S, Jackson RS II, Revelo MP, Bhowmick NA \& Hayward SW 2011 Altered TGF- $\beta$ signaling in a subpopulation of human stromal cells promotes prostatic carcinogenesis. Cancer Research 71 1272-1281. (doi:10.1158/0008-5472.CAN-10-3142)

Fuzio P, Ditonno P, Rutigliano M, Battaglia M, Bettocchi C, Loverre A, Grandaliano G \& Perlino E 2012 Regulation of TGF- $\beta 1$ expression by androgen deprivation therapy of prostate cancer. Cancer Letters $\mathbf{3 1 8}$ 135-144. (doi:10.1016/j.canlet.2011.08.034)

Hara T, Miyazaki H, Lee A, Tran CP \& Reiter RE 2008 Androgen receptor and invasion in prostate cancer. Cancer Research 68 1128-1135 (doi:10.1158/0008-5472.CAN-07-1929)

Imada K, Shiota M, Kohashi K, Kuroiwa K, Song Y, Sugimoto M, Naito S \& Oda Y 2013 Mutual regulation between Raf/MEK/ERK signaling and Y-box-binding protein-1 promotes prostate cancer progression. Clinical Cancer Research 19 4638-4650. (doi:10.1158/1078-0432.CCR-12-3705)

Jacob K, Bosserhoff AK, Wach F, Knüchel R, Klein EC, Hein R \& Buettner R 1995 Characterization of selected strongly and weakly invasive sublines of a primary human melanoma cell line and isolation of subtractive cDNA clones. International Journal of Cancer. Journal International du Cancer 60 668-675. (doi:10.1002/ijc.2910600517)

Kang HY, Huang KE, Chang SY, Ma WL, Lin WJ \& Chang C 2002 Differential modulation of androgen receptor-mediated transactivation by Smad3 and tumor suppressor Smad4. Journal of Biological Chemistry 277 43749-43756. (doi:10.1074/jbc.M205603200)

Kwok WK, Ling MT, Lee TW, Lau TC, Zhou C, Zhang X, Chua CW, Chan KW, Chan FL, Glackin C et al. 2005 Up-regulation of TWIST in prostate cancer and its implication as a therapeutic target. Cancer Research 65 5153-5162. (doi:10.1158/0008-5472.CAN-04-3785) 
Lamoureux F, Thomas C, Yin MJ, Kuruma H, Beraldi E, Fazli L, Zoubeidi A \& Gleave ME 2011 Clusterin inhibition using OGX-011 synergistically enhances Hsp90 inhibitor activity by suppressing the heat shock response in castrate-resistant prostate cancer. Cancer Research $\mathbf{7 1}$ 5838-5849. (doi:10.1158/0008-5472.CAN-11-0994)

Laping NJ, Everitt JI, Frazier KS, Burgert M, Portis MJ, Cadacio C, Gold LI \& Walker CL 2007 Tumor-specific efficacy of transforming growth factor- $\beta$ RI inhibition in Eker rats. Clinical Cancer Research 13 3087-3099. (doi:10.1158/1078-0432.CCR-06-1811)

Li R, Wheeler T, Dai H, Frolov A, Thompson T \& Ayala G 2004 High level of androgen receptor is associated with aggressive clinicopathologic features and decreased biochemical recurrence-free survival in prostate: cancer patients treated with radical prostatectomy. American Journal of Surgical Pathology 28 928-934. (doi:10.1097/00000478-200407000-00013)

Li Y, Alsagabi M, Fan D, Bova GS, Tewfik AH \& Dehm SM 2011 Intragenic rearrangement and altered RNA splicing of the androgen receptor in a cell-based model of prostate cancer progression. Cancer Research $\mathbf{7 1}$ 2108-2117. (doi:10.1158/0008-5472.CAN-10-1998)

Liu YN, Liu Y, Lee HJ, Hsu YH \& Chen JH 2008 Activated androgen receptor downregulates E-cadherin gene expression and promotes tumor metastasis. Molecular and Cellular Biology 28 7096-7108. (doi:10.1128/ MCB.00449-08)

Liu LL, Xie N, Sun S, Plymate S, Mostaghel E \& Dong X 2014 Mechanisms of the androgen receptor splicing in prostate cancer cells. Oncogene $\mathbf{3 3}$ 3140-3150. (doi:10.1038/onc.2013.284)

Lucas JM, Heinlein C, Kim T, Hernandez SA, Malik MS, True LD, Morrissey C, Corey E, Montgomery B, Mostaghel E et al. 2014 The androgen-regulated protease TMPRSS2 activates a proteolytic cascade involving components of the tumor microenvironment and promotes prostate cancer metastasis. Cancer Discovery 4 1310-1325. (doi:10.1158/2159-8290.CD-13-1010)

Miyamoto DT, Lee RJ, Stott SL, Ting DT, Wittner BS, Ulman M, Smas ME, Lord JB, Brannigan BW, Trautwein J et al. 2012 Androgen receptor signaling in circulating tumor cells as a marker of hormonally responsive prostate cancer. Cancer Discovery 2 995-1003. (doi:10.1158/ 2159-8290.CD-12-0222)

Perry KT, Anthony CT, Case T \& Steiner MS 1997 Transforming growth factor $\beta$ as a clinical biomarker for prostate cancer. Urology 49 151-155. (doi:10.1016/S0090-4295(96)00426-8)

Scher HI, Halabi S, Tannock I, Morris M, Sternberg CN, Carducci MA, Eisenberger MA, Higano C, Bubley GJ, Dreicer R et al. 2008 Design and end points of clinical trials for patients with progressive prostate cancer and castrate levels of testosterone: recommendations of the Prostate Cancer Clinical Trials Working Group. Journal of Clinical Oncology 26 1148-1159. (doi:10.1200/JCO.2007.12.4487)

Schmalhofer O, Brabletz S \& Brabletz T 2009 E-cadherin $\beta$-catenin, and ZEB1 in malignant progression of cancer. Cancer Metastasis Reviews 28 151-166. (doi:10.1007/s10555-008-9179-y)

Shah PP \& Kakar SS 2011 Pituitary tumor transforming gene induces epithelial to mesenchymal transition by regulation of Twist, Snail, Slug, and E-cadherin. Cancer Letters 311 66-76. (doi:10.1016/j.canlet.2011.06.033)

Sharifi N, Gulley JL \& Dahut WL 2010 An update on androgen deprivation therapy for prostate cancer. Endocrine-Related Cancer 17 R305-R315. (doi:10.1677/ERC-10-0187)

Shiota M, Yokomizo A, Tada Y, Inokuchi J, Kashiwagi E, Masubuchi D, Eto M, Uchiumi T \& Naito S 2010 Castration resistance of prostate cancer cells caused by castration-induced oxidative stress through Twist 1 and androgen receptor overexpression. Oncogene 29 237-250. (doi:10.1038/onc.2009.322)

Shiota M, Takeuchi A, Song Y, Yokomizo A, Kashiwagi E, Uchiumi T, Kuroiwa K, Tatsugami K, Fujimoto N, Oda Y et al. 2011 a Y-box binding protein-1 promotes castration-resistant prostate cancer growth via androgen receptor expression. Endocrine-Related Cancer 18 507-514. (doi:10.1530/ERC-11-0017)

Shiota M, Yokomizo A \& Naito S $2011 b$ Oxidative stress and androgen receptor signaling in the development and progression of castrationresistant prostate cancer. Free Radical Biology \& Medicine 51 1320-1328. (doi:10.1016/j.freeradbiomed.2011.07.011)

Shiota M, Zardan A, Takeuchi A, Kumano M, Beraldi E, Naito S, Zoubeidi A \& Gleave ME 2012a Clusterin mediates TGF- $\beta$-induced epithelial-mesenchymal transition and metastasis via Twist 1 in prostate cancer cells. Cancer Research 72 5261-5272. (doi:10.1158/0008-5472.CAN-12-0254)

Shiota M, Song Y, Takeuchi A, Yokomizo A, Kashiwagi E, Kuroiwa K, Tatsugami K, Uchiumi T, Oda Y \& Naito S 2012b Antioxidant therapy alleviates oxidative stress by androgen deprivation and prevents conversion from androgen dependent to castration resistant prostate cancer. Journal of Urology 187 707-714. (doi:10.1016/j.juro.2011.09.147)

Shiota M, Takeuchi A, Yokomizo A, Kashiwagi E, Tatsugami K \& Naito S $2012 c$ Methyltransferase inhibitor adenosine dialdehyde suppresses androgen receptor expression and prostate cancer growth. Journal of Urology 188 300-306. (doi:10.1016/j.juro.2012.02.2553)

Shiota M, Kashiwagi E, Yokomizo A, Takeuchi A, Dejima T, Song Y, Tatsugami K, Inokuchi J, Uchiumi T \& Naito S 2013a Interaction between docetaxel resistance and castration resistance in prostate cancer: implications of Twist1, YB-1, and androgen receptor. Prostate 73 1336-1344. (doi:10.1002/pros.22681)

Shiota M, Bishop JL, Nip KM, Zardan A, Takeuchi A, Cordonnier T, Beraldi E, Bazov J, Fazli L, Chi Ket al. $2013 b$ Hsp27 regulates epithelial mesenchymal transition, metastasis, and circulating tumor cells in prostate cancer. Cancer Research 73 3109-3119. (doi:10.1158/0008-5472.CAN-12-3979)

Shiota M, Yokomizo A, Takeuchi A, Imada K, Kashiwagi E, Song Y, Inokuchi J, Tatsugami K, Uchiumi T \& Naito S 2014 Inhibition of protein Kinase $\mathrm{C} /$ Twist1 signaling augments anti-cancer effects of androgen deprivation and enzalutamide in prostate cancer. Clinical Cancer Research 20 951-961. (doi:10.1158/1078-0432.CCR-13-1809)

Sun Y, Wang BE, Leong KG, Yue P, Li L, Jhunjhunwala S, Chen D, Seo K, Modrusan Z, Gao WQ et al. 2012 Androgen deprivation causes epithelial-mesenchymal transition in the prostate: implications for androgen-deprivation therapy. Cancer Research 72 527-536. (doi:10. 1158/0008-5472.CAN-11-3004)

Tanaka H, Kono E, Tran CP, Miyazaki H, Yamashiro J, Shimomura T, Fazli L, Wada R, Huang J, Vessella RL et al. 2010 Monoclonal antibody targeting of N-cadherin inhibits prostate cancer growth, metastasis and castration resistance. Nature Medicine 16 1414-1420. (doi:10.1038/nm.2236)

Thiery JP \& Sleeman JP 2006 Complex networks orchestrate epithelialmesenchymal transitions. Nature Reviews. Molecular Cell Biology 7 131-142. (doi:10.1038/nrm1835)

Wolff JM, Fandel T, Borchers H, Brehmer B Jr \& Jakse G 1998 Transforming growth factor- $\beta 1$ serum concentration in patients with prostatic cancer and benign prostatic hyperplasia. British Journal of Urology 81 403-405. (doi:10.1046/j.1464-410x.1998.00560.x)

Ye L, Mason MD \& Jiang WG 2011 Bone morphogenetic protein and bone metastasis, implication and therapeutic potential. Frontiers in Bioscience 16 865-897. (doi:10.2741/3725)

Zeisberg M \& Neilson EG 2009 Biomarkers for epithelial-mesenchymal transitions. Journal of Clinical Investigation 119 1429-1437. (doi:10. 1172/JCI36183)

Zhu ML \& Kyprianou N 2010 Role of androgens and the androgen receptor in epithelial-mesenchymal transition and invasion of prostate cancer cells. FASEB Journal 24 769-777. (doi:10.1096/fj.09-136994)

Zhu ML, Partin JV, Bruckheimer EM, Strup SE \& Kyprianou N 2008 TGF- $\beta$ signaling and androgen receptor status determine apoptotic cross-talk in human prostate cancer cells. Prostate 68 287-295. (doi:10.1002/pros.20698)

Received in final form 24 August 2015

Accepted 26 August 2015

Made available online as an Accepted Preprint 26 August 2015

Published by Bioscientifica Ltd. http://erc.endocrinology-journals.org

DOI: $10.1530 / E R C-15-0225$
(C) 2015 Society for Endocrinology Printed in Great Britain 